\title{
Influence of Urbach Energy with Solution Molarity on the Electrical Conductivity in Undoped ZnO Thin Films
}

\author{
Said Benramache ${ }^{*}$, Boubaker Benhaoua ${ }^{2}$ \\ 1 Material Sciences Department, Faculty of Technology, University of Biskra, Biskra 07000, Algeria \\ ${ }^{2}$ VTRS Laboratory, Institute of Technology, University of El-Oued, El-Oued 39000, Algeria
}

(Received 17 March 2016; published online 21 June 2016)

\begin{abstract}
This paper presents the results concerning the new correlation between electrical conductivity and Urbach energy was investigated as a function of solution molaritie in $\mathrm{ZnO}$ thin films. The model proposals were based on experimental data as discussed in our published paper. ZnO thin films were prepared into the ultrasonic spray method with different solution molarities on glass substrate at $350{ }^{\circ} \mathrm{C}$. The measurement data's showing that the electrical conductivity of undoped $\mathrm{ZnO}$ thin films can be estimated by varying the Urbach energy and the concentration of $\mathrm{ZnO}$ solution, which were found that the correlate values of electrical conductivities are in qualitative agreements with experimental data's. Because, it was in high correlation coefficient can be varied in the range between $0.97-0.99 \%$. The high agreement was found in the calculation and achieved in Eq. (4) with maximum relative errors values were limited to zero \%, due to the sign plus was found between parameters correlates.
\end{abstract}

Keywords: $\mathrm{ZnO}$, Thin films, Electrical conductivity, Urbach energy, Correlation.

\section{INTRODUCTION}

Zinc oxide is a direct, wide band gap semiconductor material, which is already used in various practical applications, such as optoelectronics, transparent electronics, spintronic devices, antireflection coatings transparent electrodes in solar cells and gas sensor applications [1-6]. $\mathrm{ZnO}$ which is one of the most important binary II-VI semiconductor compounds a natural n-type electrical conductivity with a direct energy wide band gap of $3.37 \mathrm{eV}$ at room temperature, a large exciton binding energy ( $60 \mathrm{meV})$ [7-9].

The resistivity values of $\mathrm{ZnO}$ films may be adjusted between $10^{-3} \Omega \mathrm{cm}$ and $10^{-5} \Omega \mathrm{cm}$ by changing the annealing conditions and doping [10]. Currently, many methods are being used to prepare $\mathrm{ZnO}$ films, such as molecular beam epitaxy (MBE), chemical vapor deposition, electrochemical deposition, pulsed laser deposition (PLD), sol-gel process, reactive evaporation, magnetron sputtering technique and spray pyrolysis [11-16].

The aim of this work is study the possibility to calculate of the electrical conductivity of the undoped $\mathrm{ZnO}$ thin films with their Urbach energy at different solution molarities. Ishizuka et al. [17] studied the correlation of the cell performance of wide-gap CIGS cells with highly resistive i-ZnO layers of different thickness; found that cell parameters, in particular, the fill factor (F.F.) varied with the thickness of the i-ZnO layers and the variation of the F.F. However, same works were investigated the relationships of physical properties of $\mathrm{ZnO}$ thin film as a function of parameters conditions [18-23]. The electrical conductivity and Urbach energy of $\mathrm{ZnO}$ thin films has been used for these correlations were taken from our published paper which was deposited on glass substrate at different solution molarities by ultrasonic spray method, as discussed with [24].

\footnotetext{
*saidbenramache07@ gmail.com
}

\section{METHODOLOGY}

\subsection{Materials and Methods}

The spray solution were prepared by dissolving ( $\mathrm{Zn}(\mathrm{CH} 3 \mathrm{COO}) 2,2 \mathrm{H} 2 \mathrm{O})$ in the solvent containing equal volumes absolute ethanol solution (99.995 \%) purity, then added a drops of $\mathrm{HCl}$ solution as a stabilized, the mixture solution was stirred at $50{ }^{\circ} \mathrm{C}$ for $180 \mathrm{~min}$ to yield a clear and transparency solution.

The optical properties of the deposited films was measured in the range of $300-800 \mathrm{~nm}$ using an ultravioletvisible spectrophotometer (UV, Lambda 35) and the electrical conductivity of the films was measured in a coplanar structure obtained with evaporation of four golden stripes on film surface.

The $\mathrm{ZnO}$ samples were deposited on glass substrates using the ultrasonic spray technique. The films were deposited at a substrate temperature of $350{ }^{\circ} \mathrm{C}$ with 2 minutes of deposition time were realized in our published paper [24]. The optical properties and electrical conductivity of the films were studied as a function of the effect of solution molarity (see Table 1).

Table 1 - The optical band gap energy, the Urbach energy and electrical conductivity for $\mathrm{ZnO}$ thin films were measured as a function of solution molarity [24]

\begin{tabular}{|lllll|}
\hline $\mathrm{M}(\mathrm{mol} / \mathrm{l})$ & 0.05 & 0.075 & 0.01 & 0.125 \\
\hline$E_{g}(\mathrm{eV})$ & 3.08 & 3.22 & 3.37 & 3.15 \\
$E_{u}(\mathrm{meV})$ & 922.1 & 318.6 & 85.8 & 175.7 \\
$\sigma(\Omega . c m)-1$ & 0.24 & 2.38 & 7.66 & 7.96 \\
\hline
\end{tabular}

As can be seen in Table 1, that a minimum Urbach energy were reached of $0.1 \mathrm{M}$, which means the adequate concentration for less disorder, as expressed in the literatures $[12,25]$, they found that the minimum Urbach energies were reached with $\mathrm{ZnO}$ thin films obtained by 
ethanol and methanol solutions. This can be explained by variation of optical gap energy (see Table 1).

\subsection{Modelling and Methods}

The correlation between the electrical and optical properties were studied for the electrical conductivity $(\sigma)$ as a function of Urbach energy $\left(E_{u}\right)$ and solution molarity $\mathrm{M}$ of $\mathrm{ZnO}$ films. The correlate parameters were obtained by the following equation:

$$
\left\{\begin{array}{l}
\sigma_{\left(^{*}\right)}=\frac{\sigma_{(e)}}{\sigma_{(e) \operatorname{Max}}} \\
E_{u(*)}=\frac{E_{u(e)}}{E_{u(e) \operatorname{Max}}} \\
M_{\left(^{*}\right)}=\frac{M_{(e)}}{M_{(e) \operatorname{Max}}}
\end{array}\right.
$$

where $\sigma_{(e)}, \quad E_{u(e)}$ and $M_{(e)}$ are the experimental values; $\sigma_{(e) \operatorname{Max}}, \quad E_{u(e) \operatorname{Max}}$ and $M_{(e) \operatorname{Max}}$ are maximal experimental values and $\sigma_{\left(^{*}\right)}, E_{\left.u^{*}\right)}$ and $M_{\left(^{*}\right)}$ are the first values that have been consisted in the correlated relationships, this model was used to deleted the form units of the electrical conductivity, Urbach energy and solution molarity.

\subsection{Relation Between the Electrical Conductivity and Urbach Energy}

The variation of electrical conductivity of $\mathrm{ZnO}$ thin films as a function of solution molarity as shown in Table 1, as can be seen, the maximum electrical conductivity of the $\mathrm{ZnO}$ was 7.96 an $(\Omega \cdot \mathrm{cm})^{-1}$ for sprayed film at $0.125 \mathrm{M}$. The increase of the electrical conductivity with solution molarity can be explained by the increase in carrier concentration [26].

We have used the Urbach energy $\left(E_{u}\right)$, which is related to the disorder in the film network, as it is expressed follow [27]:

$$
A=A_{0} \exp \left(\frac{h v}{E_{u}}\right)
$$

where $A_{0}$ is a constant $h v$ is the photon energy and $E_{u}$ is the Urbach energy, the latter decreased with increasing the band gap is indicating the decrease of defects as it was illustrated in (Table 1) [28].

We have descript previously the experimental data (see Table 1); one can be seen from this data, the electrical conductivity of $\mathrm{ZnO}$ thin films change in the form nonlinear with the Urbach energy and solution molarity. We have used different models proposals in this study to estimate the electrical conductivity, these models were discussed in the follow steps.

Firstly, we have used the relationships in the form nonlinear to calculate the electrical conductivity from the Urbach energy and solution molarity. The following relationships are evaluated in this step:

$$
\sigma_{(c)}=\frac{M_{\left(^{*}\right)}}{a+b \times E_{u(*)}{ }^{2}}
$$

where $\sigma_{(c)}$ is the correlate electrical conductivity, $a$ and $b$ are empirical constants as $a \approx 0.738306$, and $b \approx 8.40603$.

$$
\sigma_{(c)}=\frac{a+M_{\left(^{*}\right)}}{b+c \times E_{u(*)}^{2}}
$$

where $\sigma_{(c)}$ is the correlate electrical conductivity, $a, b$ and $c$ are empirical constants as $a \approx-0.20205, \quad b \approx 0.56601$ and $c \approx 6.391$

Secondary, we have evaluated different relationships to compare the estimate values with the first steps as used the following relationships:

$$
\sigma_{(c)}=a \times M_{(*)}^{\left(b \times E_{u(*)}\right)}
$$

where $a$ and $b$ are empirical constants as $a \approx 1.04241$, and $b \approx 6.71579$.

$$
\sigma_{(c)}=a \times M_{\left(^{*}\right)}^{\left(b+c \times \operatorname{Ln} E_{u^{(*)}}\right)}
$$

where $a, b$ and $c$ are empirical constants as $a \approx 1.0002$, $b \approx 4.1155$ and $c \approx 1.6592$.

$$
\sigma_{(c)}=a \times\left(b^{E_{u^{(*)}}}\right) \times M_{(*)}^{c}
$$

where $a, b$ and $c$ are empirical constants as $a \approx 1.7523$, $b \approx 0.052704$ and $c \approx 1.4609$.

In the end, we have used another formula to limit all application ranges of this calculation, which considered as an aim will have realized. We found the following empirical relationship in this step:

$$
\sigma_{(c)}=a \times \exp \left(b \times E_{u(*)}+c \times M_{\left(^{*}\right)}^{2}\right)
$$

where $a, b$ and $c$ are empirical constants as $a \approx 0.68017$, $b \approx-3.454$ and $c \approx 1.0437$.

$$
\sigma_{(c)}=a \times \exp \left(\frac{b}{M_{\left(^{*}\right)}}+c \times E_{u(*)}\right)
$$

where $a, b$ and $c$ are empirical constants as $a \approx 5.4156$, $b \approx-1.1862$ and $c \approx-2.6397$.

\section{RESULTS AND DISCUSSION}

In this study, we will show the evolution of the solution molarity on the correlation between the electrical conductivity and Urbach energy, we tried to establish correlations for each model proposed. The $\mathrm{ZnO}$ thin films exhibit a good electrical conductivity which was calculated from different solution molarities can be measured with the Urbach energy.

As shown in Fig. 1, 2 and 3. Significant the correlate electrical conductivities with the original values of experimental, which were measured as a function of the Urbach energy and solution molarity ( $\mathrm{ZnO}$ concentration) of the $\mathrm{ZnO}$ thin films, which calculated using the 
previously steps (section 2.3) using the Eq. (3) to Eq. (9), respectively. As can be seen, all measurements of the electrical conductivities of $\mathrm{ZnO}$ thin films by each model proposed are equal to the experimental values (see Figures 1 to 3), because the high correlation coefficient which was found. Thus the relative errors of these calculations were found are smaller than $20 \%$ of the solution molarity higher than 0.075 M. From these correlations indicate that the measurement of the electrical conductivity of our undoped thin films by the proposed equations; it is equal to the experimental data,

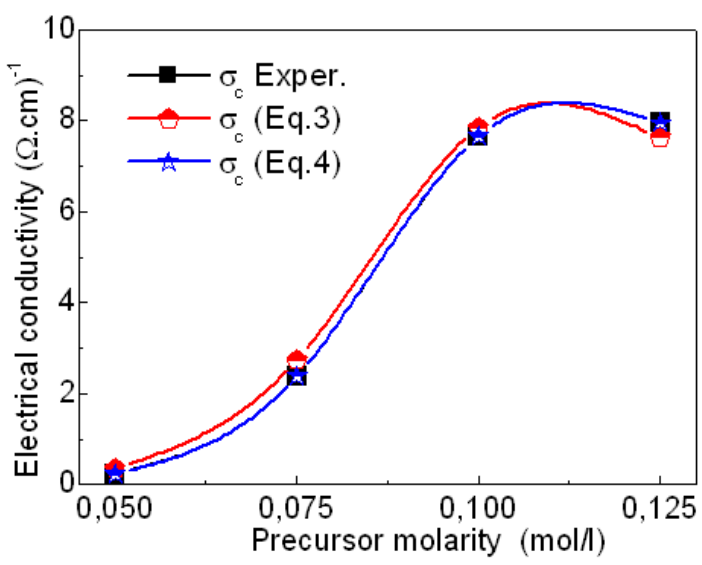

Fig. 1 - The experimental electrical conductivity and correlations of $\mathrm{ZnO}$ thin films for the Eq. (3) and Eq. (4) as a function of the solution molarity

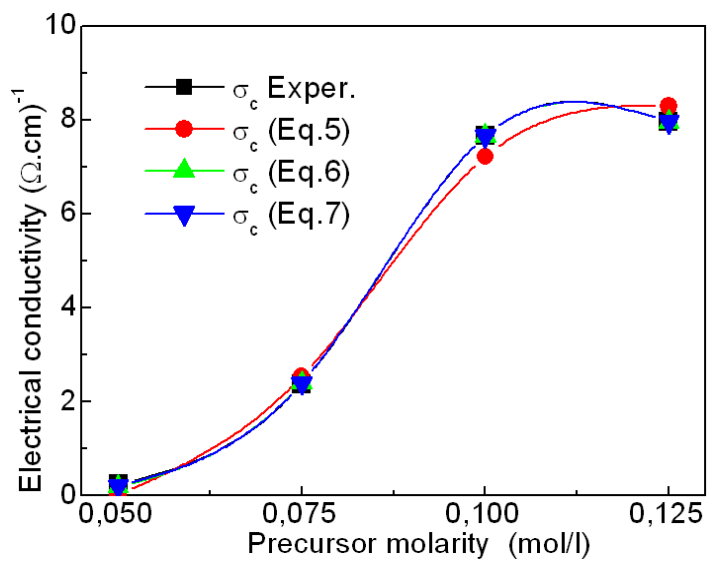

Fig. 2 - The experimental electrical conductivity and correlations of $\mathrm{ZnO}$ thin films for the Eq. (5), Eq. (6) and Eq. (7) as a function of the solution molarity

The relative error values were measured by the following relationship

$$
\left|\left(G_{E x p}-G_{C o r r}\right) / G_{E x p}\right| \times 100
$$

where $\sigma_{(e)}$ and $\sigma_{(c)}$ are the experimental and correlate values, respectively.

In our experience there was no evidence for significant changes in electrical conductivity with correlation upon varying the Urbach energy by modifying the solution molarity; the main effects have been observed upon variation of the model proposals. As can be seen in Fig. 4 the $\mathrm{ZnO}$ solution $0.1 \mathrm{M}$ is achieved the relative error was limited to zero \% in some proposed models, can be explain by the optimal point and the maximum enhancement of the electrical conductivity. Based on the observation of theoretical method can be found that the correlation values for the electrical conductivity were investigated, which it is good agreement was found between the calculated and experimental values. The best calculated results are achieved in Eq. (4) with maximum relative errors values were limited to zero \%, due to the sign plus was found between parameters correlates.

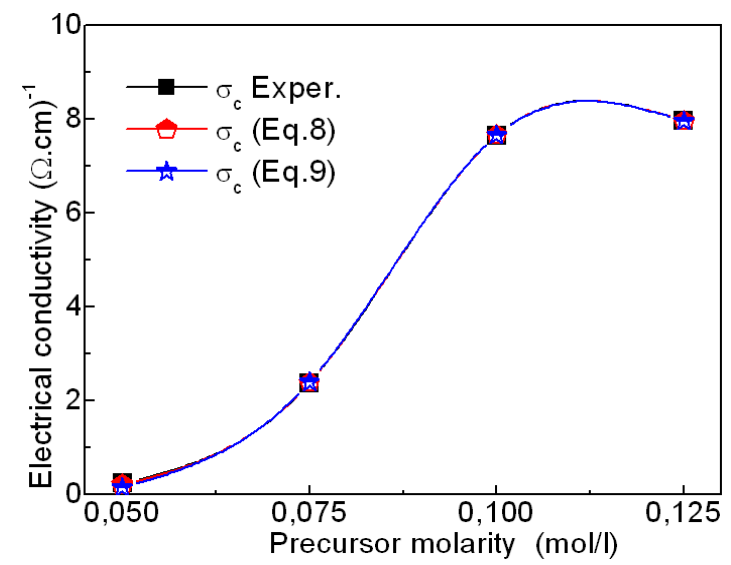

Fig. 3 - The experimental electrical conductivity and correlations of $\mathrm{ZnO}$ thin films for the Eq. (8) and Eq. (9) as a function of the solution molarity

Thus result indicates that such $\mathrm{ZnO}$ thin films sprayed with $0.1 \mathrm{M}$ are chemically purer and have many fewer defects and less disorder owing to an almost complete chemical decomposition. The $\mathrm{ZnO}$ solution $0.1 \mathrm{M}$ can be considered the optimal point to get good quality such as high conductivity, good transparency and higher crystallinity. Thus the correlations between the electrical conductivity and the Urbach energy with the solution molarity were investigated.

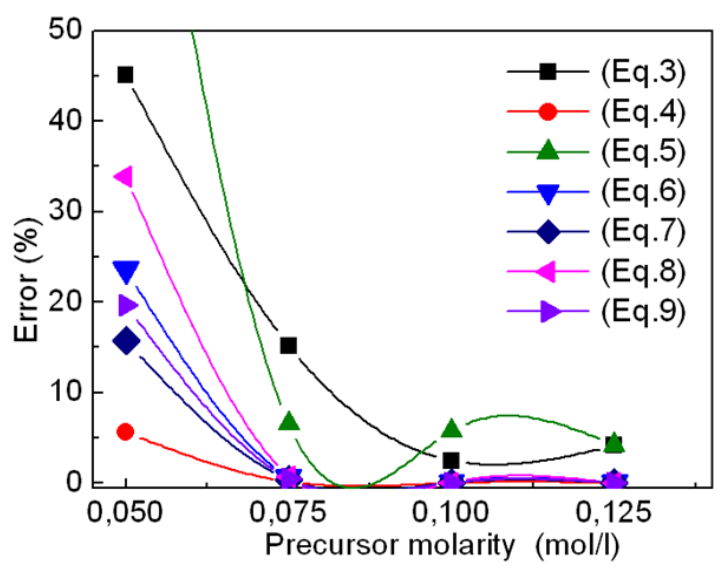

Fig. 4 - The variation of errors of $\mathrm{ZnO}$ thin films as a function of solution molarity for all formulas

\section{CONCLUSION}

In summary, the $\mathrm{ZnO}$ thin films were prepared with different solution molarities by ultrasonic spray method on glass substrate at $350{ }^{\circ} \mathrm{C}$. This paper is to present a new approach to the description of correlation between 
electrical conductivity and Urbach energy by varying the solution molaritie. The model proposals to estimate the electrical conductivity of undoped $\mathrm{ZnO}$ thin films were investigated. From the measurements data's, it were found that the correlate value of electrical conductivities are in qualitative agreements with experimental data's, which

\section{REFERENCES}

1. H. Aydin, H.M. El-Nasser, C. Aydin, A.A. Al-Ghamdi, F. Yakuphanoglu, Appl. Surf. Sci. 350, 109 (2015).

2. S. Zhao, L. Yang, Y. Zhou, K. Zhao, Optik 122, 960 (2011).

3. C.F. Wang, B. Hu, H.H. Yi, Optik 123, 1040 (2012).

4. J.S. Jeng, Z. Ben Ayadi, Microelectron. Eng. 149, 1 (2016).

5. A.J. Hashim, M.S. Jaafar, A.J. Ghazai, N.M. Ahmed, Optik 124, 491 (2013).

6. Y. Guodong, W. Minqiang, Y. Zhi, J. Semiconductors 36 No 8, 084006 (2015).

7. M. Tomakin, Superlattice. Microstruct. 51, 372 (2012).

8. Y. Zhang, C. Wu, Y. Zheng, J. Semiconductors 33 No 2, 023001 (2012).

9. Shadia J. Ikhmayies, Naseem M. Abu El-Haija, Riyad N. Ahmad-Bitar, J. Semiconductors 36 No 3, 033005 (2015).

10. S. Benramache, O. Belahssen, Optik 125, 1303 (2014).

11. A. Gahtar, S. Benramache, B. Benhaoua, J. Semiconductors 34 No 7, 073001 (2013).

12. S. Benramache, B. Benhaoua, N. Khechai, Matériaux Techniq. 100, 573 (2012).

13. H.L. Ma, Z.W. Liu, D.C. Zeng, M.L. Zhong, H.Y. Yu, E. Mikmekova, Appl. Surf. Sci. 283, 1006 (2013).

14. S. Benramache, O. Belahssen, H. Ben J. Semiconductors 35 No 7, 073001 (2014).

15. S. Benramache, B. Benhaoua, Optik 124, 3221 (2013).

16. M.A. Mahadik, Y.M. Hunge, S.S. Shinde, K.Y. Rajpure, was in high correlation coefficient can be varied in the range between 0.97-0.99 \%. The high agreement was found in the calculation and achieved in Eq. (4) with maximum relative errors values were limited to zero \%, due to the sign plus was found between parameters correlates.

C.H. Bhosale, J. Semiconductors 36 No 3, 033002 (2015).

17. S. Ishizuka, K. Sakurai, A. Yamada, K. Matsubara, Sol. Energ. Mater. Sol. C. 87, 541 (2005)

18. O. Kappertz, R. Drese, M. Wuttig, J. Vac. Sci. Technol. A 20 , 2084 (2002).

19. I.V. Tudose, P. Horvath, M. Suchea, S. Christoulakis, T. Kitsopoulos, G. Kiriakidis, Appl. Phys. A 89, 57 (2007).

20. B. Joshi, S. Ghosh, P. Srivastava, P. Kumar, D. Kanjilal, Appl. Phys. A 107, 393 (2012).

21. S.D. Wang, T. Miyadera, T. Minari, Y. Aoyagi, K. Tsukagoshi, Appl. Phys. Lett. 93, 043311 (2008).

22. J.J. Zhu, L. Vines, T. Aaltonen, A.Y. Kuznetsov, Microelectron. J. 40, 232 (2009).

23. R.S. Ajimsha, A.K. Das, B.N. Singh, P. Misra, L.M. Kukreja, Physica B 406, 4578 (2011).

24. S. Benramache, F. Chabane, D. Bensahal, O. Belahssen, F.Z. Lemmadi, J. Sci. Eng. 2, 97 (2013).

25. S. Benramache, A. Rahal, B. Benhaoua, Optik 125, 663 (2014).

26. S. Benramache, B. Benhaoua, Superlattice. Microstruct. 52, 1062 (2012).

27. S. Benramache, B. Benhaoua, et al., J. Semiconductors 33 No 9, 093001 (2012).

28. S. Benramache, B. Benhaoua, Superlattice. Microstruct. 52, 807 (2012) 